\title{
Mapeamento de locos de características quantitativas associados à composição de carcaça, no cromossomo seis de suíno
}

[Mapping of quantitative trait loci for carcass composition on swine chromosome six]

\author{
A.V. Pires ${ }^{1}$, P.S. Lopes $^{2}$, S.E.F. Guimarães ${ }^{2}$, C.T. Guimarães ${ }^{3}$, J.O. Peixoto ${ }^{2}$ \\ ${ }^{1}$ Departamento de Zootecnia - UFVJM \\ Rua da Glória, 187 \\ 39100-000 - Diamantina, MG \\ ${ }^{2}$ Departamento de Zootecnia - UFV - Viçosa, MG \\ ${ }^{3}$ Embrapa Milho e Sorgo - Sete Lagoas, MG
}

\begin{abstract}
RESUMO
Uma população de suínos, composta de 550 animais F2, foi produzida a partir do intercruzamento da geração F1, obtida pelo cruzamento divergente de dois machos da raça nativa brasileira Piau com 18 fêmeas comerciais. O objetivo do trabalho foi mapear locos de características quantitativas (QTL) associados a cortes de carcaça. Os animais foram genotipados para 13 marcadores microssatélites, distribuídos no cromossomo 6 de suínos. As características avaliadas foram: peso total do pernil, peso do pernil sem pele e sem capa de gordura, peso total da copa, peso da copa sem pele e sem capa de gordura, peso total da paleta, peso da paleta sem pele e sem capa de gordura, peso total do carré, peso do lombo, peso total do bacon, peso das costelas, peso total da papada, peso do filezinho e peso da banha rama. Utilizou-se o método de regressão por intervalo de mapeamento por meio do programa QTL Express. Foram encontrados indicativos de QTL para peso de pernil limpo, peso de paleta, peso de lombo e peso de filezinho. A região genômica deve ser saturada com marcadores adicionais para confirmar a presença de QTL reais.
\end{abstract}

Palavras-chave: suíno, QTL, cruzamento divergente, composição de carcaça, microssatélites

\begin{abstract}
A swine population of $550 \mathrm{~F} 2$ animals was produced by outbred cross using two sires of the native Brazilian breed Piau and 18 commercial dams. The animals were genotyped for 13 microsatellite markers. The evaluated composition traits of carcass were: ham weight, skinless and fatless ham weight, boston shoulder weight, skinless and fatless boston shoulder weight, picnic shoulder weight, skinless and fatless picnic shoulder weight, total loin (bone-in) weight, loin weight, bacon weight, rib weight, jowl weight, sirloin weight, and belly fat weight. Data were analyzed by multiple regression interval mapping, using the QTL Express software. Suggestive QTL were found for skinless and fatless ham weight, picnic shoulder weight, loin weight, and sirloin weight. However, the genomic region should be saturated with additional markers in order to confirm the presence of real QTL.
\end{abstract}

Keywords: swine, QTL, outbred cross, carcass composition, microsatellite

\section{INTRODUÇ̃̃O}

A agroindústria suinícola brasileira desenvolveuse muito nas últimas décadas, com ganhos significativos em diversos índices zootécnicos de desempenho. No entanto, as características relacionadas à composição de carcaça (rendimento de cortes) foram visadas apenas em um segundo momento pelos programas de melhoramento. A dificuldade de se mensurar tais características certamente é um dos principais fatores que colaboraram para isso. A utilização

Recebido em 28 de junho de 2006

Aceito em 4 de abril de 2008

E-mail: aldrinvieira@yahoo.com.br

Apoio: FAPEMIG 
das informações obtidas diretamente pela análise genômica pode contribuir para minimizar esse fato, por permitir que se avalie o desempenho dos animais nessas características sem a necessidade de abatê-los.

Uma das análises genômicas mais utilizadas na suinocultura é a porcine stress syndrome ou síndrome do estresse suíno (PSS). Estudos de biologia molecular revelaram que a PSS é resultado da mudança de uma única base na seqüência do gene receptor de rianodina (Fujii et al., 1991). Os animais portadores, homozigotos ou heterozigotos, tendem a apresentar uma qualidade de carne pior que os não portadores. Este teste tem sido usado para monitorar o alelo recessivo, causador da síndrome, nos plantéis de matrizes e reprodutores.

Análises genômicas podem ser implementadas não apenas por meio da identificação e isolamento direto de um gene que controla uma característica de interesse. A construção de mapas genéticos utilizando marcadores moleculares permite a procura por locos de característica quantitativa (QTLs) que influenciam diversas características, entre as quais, as economicamente importantes na produção animal. Dentre as estratégias de mapeamento de QTL, a escolha do delineamento para a obtenção dos indivíduos que formarão a população segregante é de extrema importância. A utilização de uma população $F_{2}$, obtida do cruzamento entre raças geneticamente divergentes, apresenta algumas vantagens como maior facilidade de detecção de QTL e grande segregação de alelos, devido à maior variabilidade genética (Andersson et al., 1998). A aplicação direta da seleção assistida por marcadores deve ser analisada para se verificar em qual raça parental estão os QTL de interesse.

A maioria dos cruzamentos em suínos para formação de uma população $F_{2}$ é obtida pelo acasalamento entre porco selvagem europeu ou porco chinês e raças comerciais, Landrace, Large White e Pietrain (Rothschild, 1994; Pig..., 1996).

Muitos estudos têm sido voltados para a busca de QTL que afetam características de carcaça em suínos (Andersson et al., 1994; Rohrer e Keele, 1998; Walling et al., 2000; Malek, et al., 2001). A maioria deles tem encontrado QTL com efeito significativo na variação fenotípica das características, ou resultados indicativos de QTL sobre as características quantitativas. A maioria dos trabalhos com características de carcaça em suínos, no entanto, utiliza informações referentes apenas a essas características propriamente ditas, como o comprimento e o rendimento de carcaça, a espessura de toucinho e a área de olho de lombo. Poucos trabalhos analisaram informações referentes ao rendimento de cortes da carcaça, que são componentes de fundamental importância para o mercado.

Segundo Rothschild e Plastow (1999), a indústria suinícola utiliza marcadores para QTL localizados no cromossomo 6. Também no cromossomo 6 estão localizados o gene associado à PSS e o gene receptor da Leptina, que são de grande interesse para a suinocultura. Por esses motivos, o cromossomo 6 foi escolhido para se iniciar a varredura genômica por QTL.

O objetivo deste trabalho foi mapear, no cromossomo 6 de suínos (SSC6), QTL associados às características de cortes de carcaça, em uma população $F_{2}$ obtida a partir de cruzamentos divergentes.

\section{MATERIAL E MÉTODOS}

A obtenção das famílias segregantes e dos dados fenotípicos foram realizadas na Granja de Melhoramento de Suínos do Departamento de Zootecnia da Universidade Federal de Viçosa (UFV), no período de novembro de 1998 a julho de 2001.

Foi utilizada uma população $\mathrm{F}_{2}$ para se obter o máximo do desequilíbrio de ligação entre os marcadores e os QTL. As famílias foram provenientes do cruzamento de dois machos da raça nativa brasileira Piau com 18 fêmeas de linhagem desenvolvida na UFV pelo acasalamento de animais de raças comerciais, Landrace, Large White e/ou Pietrain, selecionadas para características de desempenho. A geração $F_{1}$ nasceu entre os meses de março e maio de 1999. Dentre os machos $F_{1}$, 11 varrões provenientes de diferentes leitegadas foram selecionados ao acaso e acasalados (monta natural) com 54 fêmeas. Os animais foram acasalados entre os meses de fevereiro e outubro de 2000 para a produção da geração $F_{2}$, nascida entre junho de 2000 e fevereiro de 2001. Assim, os 550 animais $F_{2}$ obtidos foram distribuídos em 
cinco lotes: lote $1=$ animais nascidos entre $20 / 06 / 00$ e $03 / 07 / 00$; lote $2=$ animais nascidos entre $03 / 08 / 00$ e $23 / 08 / 00$; lote $3=$ animais nascidos entre $16 / 09 / 00$ e $01 / 11 / 00$; lote $4=$ animais nascidos entre $30 / 11 / 00$ e $25 / 12 / 00$; lote $5=$ animais nascidos entre 19/01/01 e 12/02/01. Os três primeiros lotes foram constituídos de animais nascidos de matrizes de primeira parição e os demais, de segunda parição. Os machos foram castrados aos 10 dias de idade e todos os leitões foram desmamados aos 21 dias de idade.

O abate foi realizado na própria granja onde os animais foram criados, quando atingiram cerca de $65(64,84 \pm 5,53) \mathrm{kg}$ de peso vivo e 148 $(147,83 \pm 9,95)$ dias de idade. Os animais permaneceram em jejum por 18 horas antes do abate, período em que tiveram pleno acesso à água fresca. Antes da sangria foram submetidos à insensibilização elétrica. As carcaças foram serradas longitudinalmente, incluindo a cabeça, e pesadas. A meia carcaça direita de cada animal foi resfriada à temperatura de $4^{\circ} \mathrm{C}$, por 24 horas. Após esse período, foi realizada a dissecação para se obter os dados das características de cortes das carcaças.

O DNA genômico dos parentais, $F_{1}$ e $F_{2}$, foi extraído a partir do sangue (Sambrook et al., 1989).

As amplificações foram realizadas utilizando $25 \eta$ g de DNA genômico por reação, em um volume final de $10 \mu \mathrm{l}$.
As análises dos fragmentos foram conduzidas em seqüenciador automático ABI Prism 377 do Núcleo de Biologia Aplicada da Embrapa Milho e Sorgo, Sete Lagoas, MG. A detecção dos fragmentos polimórficos amplificados e a extração dos dados em um arquivo de saída foram feitas com o auxílio dos programas GeneScan e Genotyper v.2.0 (Applied Biosystems, 2001).

Para as análises estatísticas foram utilizadas as distâncias de consenso do mapa de ligação de suínos (Tab. 1) devido a grande convergência de resultados encontrados por outros autores. Foi realizado o teste da existência de um QTL utilizando-se o programa QTL Express (Seaton et al., 2002), que emprega o método de regressão por intervalo de mapeamento desenvolvido para análises de cruzamentos entre raças divergentes (Haley et al., 1994). No modelo estatístico, assume-se que o QTL é dialélico, com alelos alternativos fixados em cada raça parental (Haley et al., 1994). Considerou-se o genótipo QQ para os animais nativos, com efeito a, qq para os animais comerciais, com efeito -a, e Qq para os animais $F_{1}$, com efeito $d$. A probabilidade de cada indivíduo $\mathrm{F}_{2}$ apresentar cada um dos três genótipos do QTL é calculada condicionalmente aos marcadores, a intervalos de um $\mathrm{cM}$ ao longo do cromossomo. Essas probabilidades são usadas para se fazer a regressão das características nos coeficientes aditivos e de dominância do QTL em estudo, para cada animal.

Tabela 1. Marcadores utilizados na varredura do cromossomo 6 de suínos

\begin{tabular}{lcccccc}
\hline Marcador & $\begin{array}{c}\text { Posição } \\
(\mathrm{cM})\end{array}$ & Fluorescência & Temp. anel. ${ }^{2}$ & $\begin{array}{c}\text { Mínimo alelo } \\
(\mathrm{pb})\end{array}$ & $\begin{array}{c}\text { Máximo alelo } \\
(\mathrm{pb})\end{array}$ & $\begin{array}{c}\text { Número de } \\
\text { alelos }\end{array}$ \\
\hline S0035 & 7,3 & Tet & 62 & 178 & 186 & 4 \\
SW973 & 18,6 & Hex & 58 & 171 & 183 & 2 \\
SW1353 & 29,2 & Hex & 58 & 154 & 168 & 4 \\
SW1841 & 41,5 & Fam & 58 & 175 & 236 & 7 \\
SW1057 & 47,1 & Hex & 56 & 150 & 188 & 7 \\
SW1067 & 71,4 & Hex & 60 & 136 & 175 & 7 \\
SW122 & 83,3 & Fam & 56 & 110 & 132 & 8 \\
DG94 & 93,0 & Hex & 56 & 174 & 190 & 4 \\
S0003 & 102,0 & Hex & 56 & 131 & 162 & 6 \\
S0228 & 105,2 & Tet & 56 & 221 & 241 & 5 \\
SW1881 & 121,1 & Fam & 58 & 151 & 183 & 5 \\
SW1680 & 153,9 & Tet & 65 & 118 & 158 & 7 \\
SW607 & 165,7 & Fam & 56 & 152 & 172 & 3 \\
\hline
\end{tabular}

${ }^{\top}$ Posição no cromossomo 6, segundo Rothschild (1994); ${ }^{2}$ temperatura de anelamento em ${ }^{\circ} \mathrm{C}$. 
Os valores da razão $\mathrm{F}$ foram plotados e os pontos com os maiores valores para a estatística do teste foram apresentados como a possível posição do provável QTL. Os níveis de significância relativos ao cromossomo ( $\alpha=0,10,0,05$ ou $0,01)$ foram obtidos pelo teste de permutação (Churchill e Doerge, 1994), utilizando-se um total de 10.000 permutações para cada característica. Para o teste de permutação usou-se o programa QTL Express (Seaton et al., 2002) e, posteriormente, o "Proc Univariate" do SAS (User's..., 1990) para se obter os níveis de significância a 1 e 5\% (QTL significativo) e a $10 \%$ (indicativo de QTL) de probabilidade, a partir das informações de todas as características simultaneamente.

Foi adotado o seguinte modelo estatístico:

$\mathrm{y}_{\mathrm{ijk}}=\mathrm{S}_{\mathrm{i}}+\mathrm{L}_{\mathrm{j}}+\left(\mathrm{C}_{\mathrm{ijk}}-\overline{\mathrm{C}}\right) \mathrm{b}+\mathrm{c}_{\mathrm{a}} \mathrm{a}+\mathrm{c}_{\mathrm{d}} \mathrm{d}+\mathrm{e}_{\mathrm{ijk}}, \quad \mathrm{em}$ que:

$\mathrm{y}_{\mathrm{ijk}}=$ fenótipo;

$\mathrm{S}_{\mathrm{i}}=$ efeito fixo do sexo i, $\mathrm{i}=1$ (macho), 2 (fêmea);

$\mathrm{L}_{\mathrm{j}}=$ efeito fixo do lote $\mathrm{j}, \mathrm{j}=1,2,3,4,5$;

$\left(\mathrm{C}_{\mathrm{ijk}}-\overline{\mathrm{C}}\right) \mathrm{b}=$ ajustamento para a covariável peso da meia carcaça direita;

$c_{a} \quad$ e $c_{d}$ foram calculados da seguinte maneira:

$\mathrm{c}_{\mathrm{a}}=\mathrm{P}(\mathrm{QQ})-\mathrm{P}(\mathrm{qq})$ e $\mathrm{c}_{\mathrm{d}}=\mathrm{P}(\mathrm{Qq})$, em que:

$\mathrm{P}(\mathrm{QQ})=$ probabilidade de os alelos do $\mathrm{QTL}$ serem homozigotos com origem nativa;

$\mathrm{P}(\mathrm{qq})=$ probabilidade de os alelos do QTL serem homozigotos com origem comercial;
$\mathrm{P}(\mathrm{Qq})=$ probabilidade de os alelos do QTL serem heterozigotos.

Este modelo foi utilizado para estimar a regressão do fenótipo nos coeficientes $c_{a}$ e $c_{d}$, variando a posição do QTL a cada cM. Para cada posição, foi calculada uma razão $\mathrm{F}$, comparando o modelo que considera a presença do QTL (modelo completo) ao modelo sem o QTL (modelo reduzido). As estimativas para a e d foram calculadas como a melhor posição estimada com a maior razão F correspondente.

\section{RESULTADOS E DISCUSSÃO}

O número de observações, as médias e os desvios-padrão das características avaliadas são apresentados na Tab. 2.

Os marcadores de microssatélites foram escolhidos de maneira a se obter uma varredura inicial do cromossomo com intervalo entre marcadores de 15 a $20 \mathrm{cM}$. Dessa forma, os marcadores utilizados se encontram a um intervalo médio de $12,7 \mathrm{cM}$, onde a menor distância entre marcador foi de $3,2 \mathrm{cM}$ e a maior distância foi de 32,8cM (Tab. 1). O marcador SW607, localizado em 165,7cM, se encontra praticamente na porção final do cromossomo, e o marcador $\mathrm{S} 0035(7,3 \mathrm{cM})$ não se encontra na porção inicial do cromossomo, que tem $167 \mathrm{cM}$.

Tabela 1. Número de observações, média e desvio-padrão para as características de cortes de suínos

\begin{tabular}{lccc}
\hline \multicolumn{1}{c}{ Característica } & $\mathrm{N}$ & Média & Desvio-padrão \\
\hline PP $(\mathrm{kg})$ & 543 & 7,2766 & 0,8207 \\
PPL (kg) & 543 & 4,9864 & 0,6039 \\
PCOPA (kg) & 549 & 2,3352 & 0,3593 \\
PCOPAL (kg) & 544 & 1,6887 & 0,2668 \\
PPA (kg) & 545 & 4,8704 & 0,6105 \\
PPAL (kg) & 548 & 2,6998 & 0,3852 \\
PC (kg) & 540 & 3,4690 & 0,4833 \\
PL (kg) & 542 & 1,0222 & 0,1816 \\
PB (kg) & 541 & 2,6891 & 0,4522 \\
PCOS (kg) & 548 & 1,5216 & 0,2460 \\
PAPADA (kg) & 546 & 0,7085 & 0,2043 \\
PF (kg) & 546 & 0,2202 & 0,0401 \\
PBR (kg) & 544 & 0,4574 & 0,1602 \\
\hline
\end{tabular}

PP: peso total do pernil; PPL: peso do pernil sem pele e sem capa de gordura; PCOPA: peso total da copa; PCOPAL: peso da copa sem pele e sem capa de gordura; PPA: peso total da paleta; PPAL: peso da paleta sem pele e sem capa de gordura; PC: peso total do carré; PL: peso do lombo; PB: peso total do bacon; PCOS: peso das costelas; PAPADA: peso total da papada; PF: peso do filezinho; PBR: peso da banha rama. 
$\mathrm{Na}$ Tab. 3 apresenta-se um resumo das estatísticas F máximas e suas posições (cM) para os prováveis QTL, com as estimativas dos efeitos aditivos e de dominância e os respectivos errospadrão, para as características de cortes. Nas Fig. 1, 2, 3 e 4 são apresentadas as distribuições das estatísticas $\mathrm{F}$ ao longo do cromossomo, onde os picos das curvas indicam as posições, em $\mathrm{cM}$, em que os prováveis QTL estão localizados.

Foram detectados três indicativos de QTL $(\mathrm{P}<0,10)$ para peso do pernil limpo, cujos valores da estatística $F$ foram 5,17 (102cM), 5,31 $(105 \mathrm{cM})$ e $4,76(129 \mathrm{cM})$, indicando que, nas respectivas posições, há indicativos de QTL associados às variações fenotípicas dessa característica (Tab. 3 e Fig. 1). Para as características; peso do pernil, peso da copa e peso da copa limpa não foram encontrados QTL significativos ou sugestivos $(\mathrm{P}>0,10)$ no cromossomo 6 de suínos.

A característica peso do pernil limpo é de extrema importância, principalmente para frigoríficos e indústria, pois está relacionada ao maior rendimento de carne na carcaça. Na região de 100 a $120 \mathrm{cM}$ está localizado o gene que codifica o receptor de rianodina ou canal liberador de cálcio (ryr-1 ou CRC1). A abertura do canal é facilitada e seu fechamento inibido, causando uma contratura involuntária e permanente do músculo. Este gene está associado com um maior desenvolvimento muscular (Coutinho, 1998), e, portanto, pode justificar os indicativos de QTL para peso do pernil limpo nessa região.

Para as características peso da paleta limpa e peso das costelas (Tab. 3 e Fig. 2), não foram encontrados QTL $(\mathrm{P}>0,10)$. No entanto, para peso da paleta, foram encontrados dois indicativos de QTL $(\mathrm{P}<0,10)$ nas posições $14 \mathrm{cM}$ $(\mathrm{F}=4,91)$ e $24 \mathrm{cM}\left(\mathrm{F}_{\max }=5,20\right)$.

Para peso do lombo verificou-se indicativo de QTL $(\mathrm{P}<0,10)$ a $130 \mathrm{cM}\left(\mathrm{F}_{\max }=8,64\right) \mathrm{e}$, para peso do filezinho, indicativo de QTL $(\mathrm{P}<0,10)$ a $78 \mathrm{cM}\left(\mathrm{F}_{\max }=4,98\right)$. Para peso do carré nenhum QTL foi detectado (Tab. 3 e Fig. 3).

Por estarem associados os QTL - peso do lombo e peso do filezinho -,, como aqueles encontrados para peso do pernil limpo e peso da paleta, são de grande interesse para os frigoríficos que visam à obtenção de melhor rendimento dos cortes com maior valor comercial, que, por sua vez, estão associados ao maior rendimento de carne. No entanto, os indicativos de QTL necessitam serem mais bem investigados, utilizando-se de mais marcadores para se ter um mapa de ligação mais saturado, o que aumenta o poder de detecção de QTL, permitindo verificar se estes são QTL de fato.

Tabela 3. Resumo das estatísticas F máximas e suas posições (cM) para os QTL, e respectivas estimativas dos efeitos aditivos e de dominância para as características de cortes de suínos

\begin{tabular}{lcccc}
\hline Característica & Posição $(\mathrm{cM})$ & $\mathrm{F}_{\max }$ & Aditivo+EP & Dominância+EP \\
\hline PP & 165 & 3,85 & $-0,0902 \pm 0,0327$ & $-0,0202 \pm 0,0515$ \\
PPL & 105 & $5,31^{1}$ & $-0,0828 \pm 0,0254$ & $0,0079 \pm 0,0375$ \\
PCOPA & 28 & 3,28 & $0,0470 \pm 0,0189$ & $0,0186 \pm 0,0299$ \\
PCOPAL & 105 & 2,76 & $-0,0302 \pm 0,0129$ & $0,0036 \pm 0,0190$ \\
PPA & 24 & 5,201 & $0,0845 \pm 0,0312$ & $-0,0807 \pm 0,0502$ \\
PPAL & 153 & 4,37 & $-0,0629 \pm 0,0213$ & $-0,0093 \pm 0,0318$ \\
PC & 72 & 3,70 & $0,0684 \pm 0,0266$ & $0,0269 \pm 0,0356$ \\
PL & 130 & $4,84^{1}$ & $0,0018 \pm 0,0125$ & $-0,0689 \pm 0,0222$ \\
PB & 101 & 2,78 & $0,0437 \pm 0,0217$ & $-0,0395 \pm 0,0315$ \\
PCOS & 102 & 1,83 & $0,0224 \pm 0,0134$ & $0,0180 \pm 0,0196$ \\
PAPADA & 98 & 3,33 & $0,0379 \pm 0,0151$ & $0,0122 \pm 0,0241$ \\
PF & 78 & 4,981 & $-0,0086 \pm 0,0028$ & $-0,0037 \pm 0,0040$ \\
PBR & 55 & 3,31 & $-0,0165 \pm 0,0124$ & $0,0429 \pm 0,0190$ \\
\hline
\end{tabular}

${ }^{1}$ indicativo a $10 \%$ de probabilidade no cromossomo 6 ; EP: erro-padrão.

PP: peso total pernil; PPL: peso do pernil limpo; PCOPA: peso total da copa; PCOPAL: peso da copa limpa; PPA: peso total da paleta; PPAL: peso da paleta limpa; PC: peso total do carré; PL: peso do lombo; PB: peso total do bacon; PCOS: peso das costelas; PAPADA: peso total da papada; PF: peso do filezinho; PBR: peso da banha rama. 


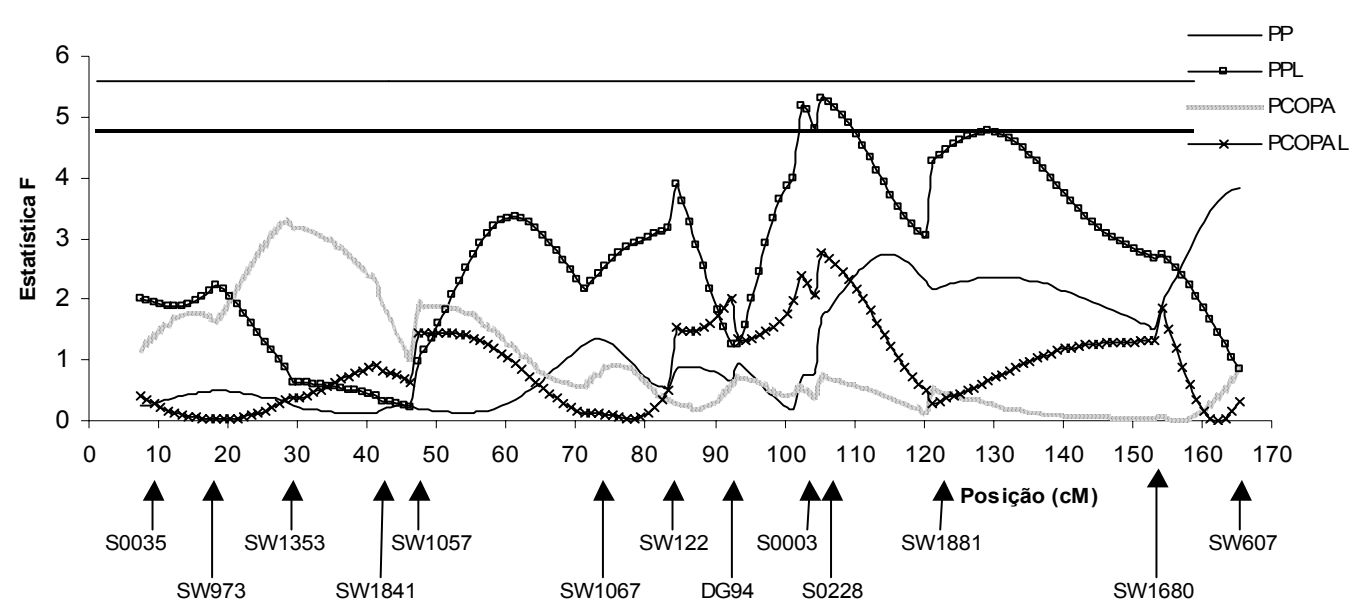

Figura 1. Estimativas da estatística $\mathrm{F}$ para: peso do pernil (PP); peso do pernil limpo (PPL); peso total da copa (PCOPA) e peso da copa limpa (PCOPAL). As linhas horizontais indicam os níveis de significância ao longo do cromossomo para QTL significativo $(5 \%=$ linha fina $)$ e QTL sugestivo $(10 \%=$ linha espessa $)$.

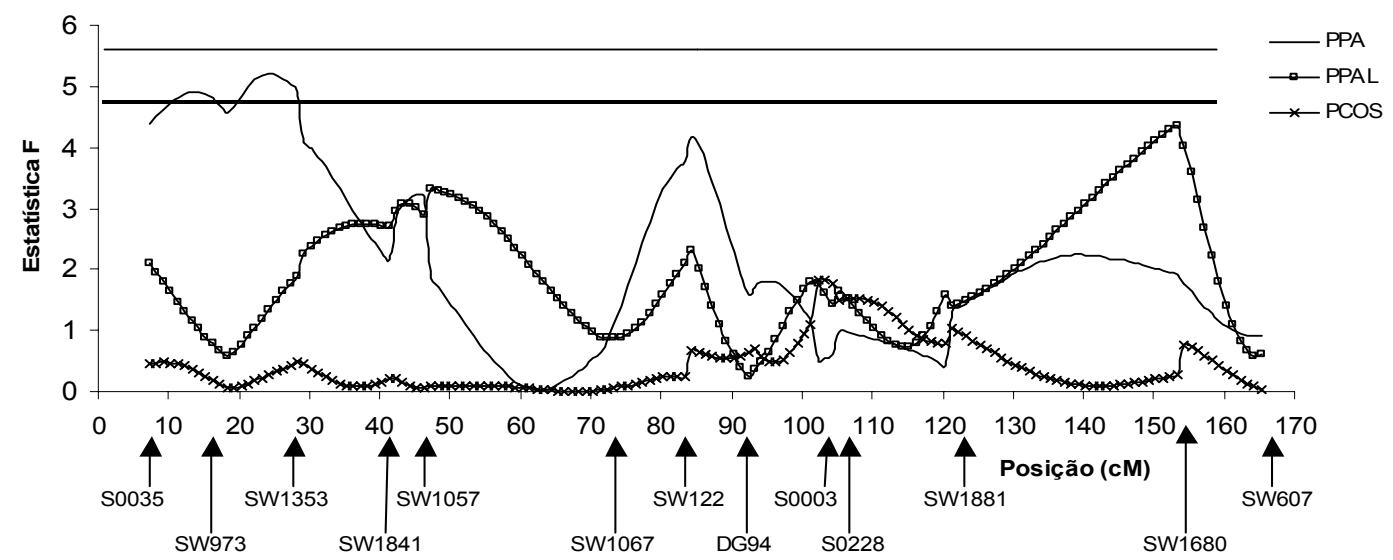

Figura 2. Estimativas da estatística F para: peso da paleta (PPA); peso da paleta limpa (PPAL) e peso das costelas (PCOS). As linhas horizontais indicam os níveis de significância ao longo do cromossomo para QTL significativo $(5 \%=$ linha fina) e QTL sugestivo $(10 \%=$ linha espessa $)$.

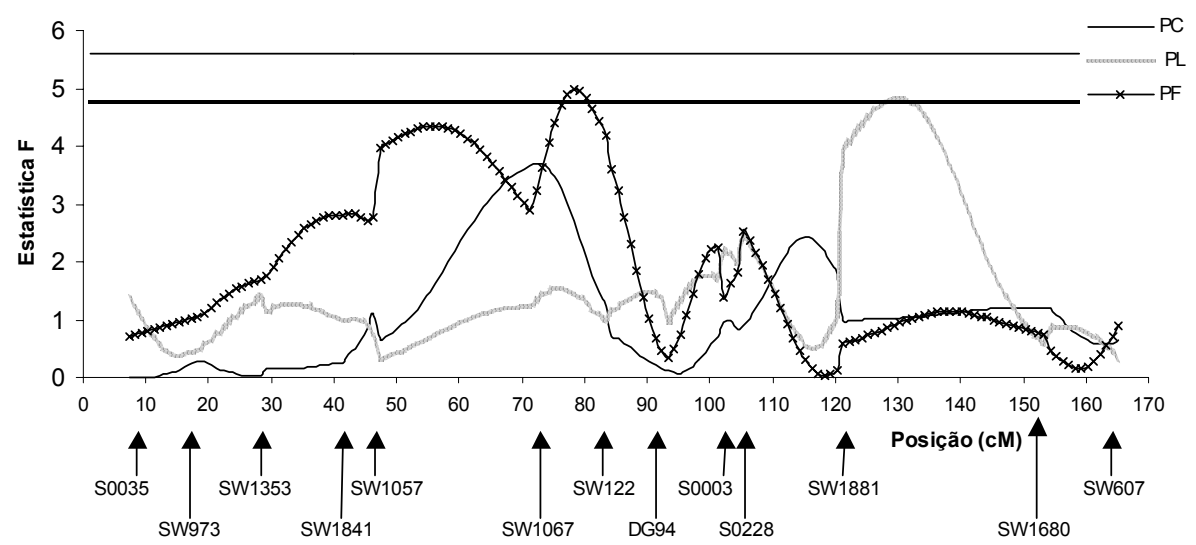

Figura 3. Estimativas da estatística F para peso do carré (PC), peso do lombo (PL) e peso do filezinho (PF). As linhas horizontais indicam os níveis de significância ao longo do cromossomo para QTL significativo $(5 \%=$ linha fina $)$ e QTL sugestivo $(10 \%=$ linha espessa). 
Quanto ao peso total do bacon, ao peso total da papada e ao peso da banha rama, nenhum QTL significativo ou indicativo de QTL foi detectado para estas características (Tab. 3 e Fig. 4).

Pires et al. (2005), ao trabalharem com o SSC6, encontraram QTL significativos para $\mathrm{pH}$, avaliados em 45 minutros após abate, e para perda de água por gotejamento. Pires et al. (2006) encontraram indicativos de QTL para as características de comprimento de carcaça, avaliadas pelo método brasileiro, e espessura de bacon, e QTL significativo para peso dos rins.

QTL para espessura de toucinho e gordura intramuscular foram encontrados no SSC6 por Koning et al. (1999) e indicativos de QTL por Ovillo et al. (2005).

Sato et al. (2003), ao analisarem o SSC6 encontraram QTL significativo para peso corporal aos 30 dias de idade e para número de dias dos 30 aos 90kg. Bidanel et al. (2001) verificaram indicativo de QTL para peso corporal às $10,13,17$ e 22 semanas de idade, para ganho de peso diário do nascimento a três semanas, de três a 10 semanas e de 10 a 22 semanas de idade, e, ainda, QTL significativo para espessura de toucinho com 13 e 17 semanas de idade. Yue et al. (2003) relataram QTL para conversão alimentar e para peso vivo ao abate, além de QTL para várias características de qualidade da carne. Ovillo et al. (2005) encontraram QTL para peso das costelas $(103 \mathrm{cM})$.

Destaca-se que poucos trabalhos usam as informações referentes às características de cortes da carcaça, principalmente pela dificuldade de serem obtidas.

Malek et al. (2001) encontraram cinco QTL para ganho de peso diário ao usarem 125 marcadores para cobrir todo o genoma suíno, enquanto que Casas-Carillo et al. (1997) relataram QTL para ganho de peso diário no cromossomo 3 suíno (SSC3). Mais ainda, Pires et al. (2007) verificaram QTL para consumo alimentar no SSC6, além de indicativo de QTL para peso aos 42 dias de idade.

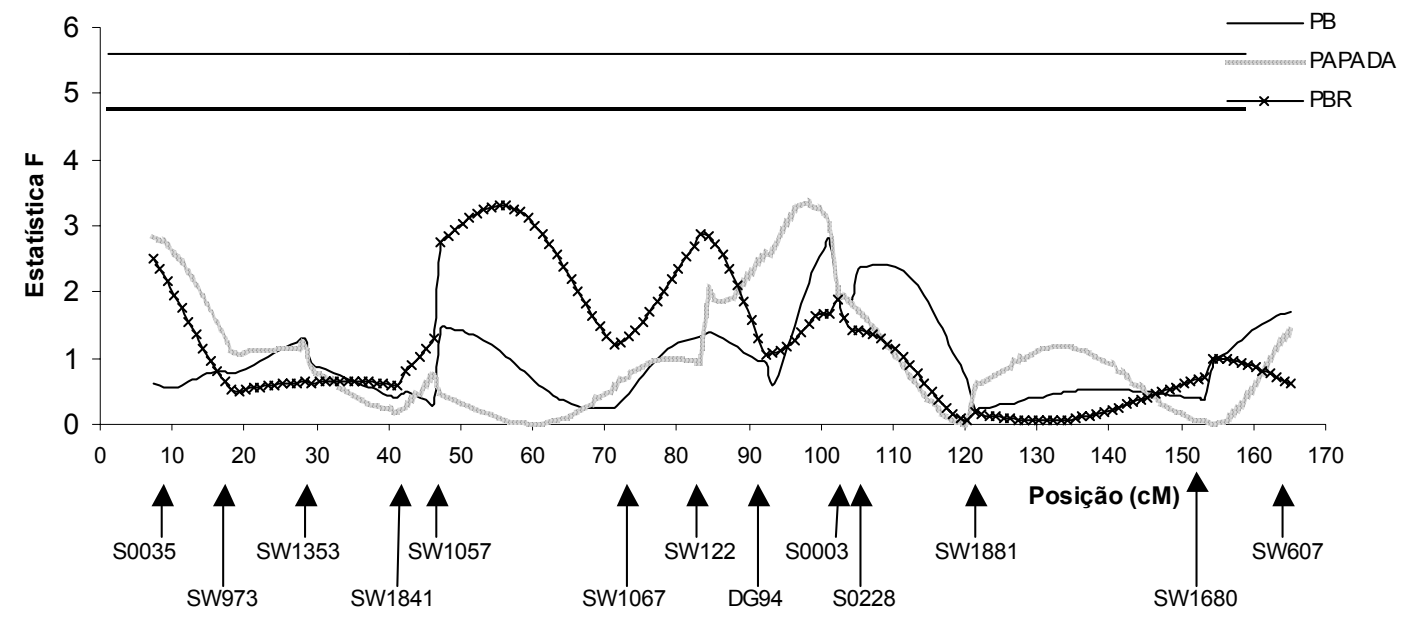

Figura 4. Estimativas da estatística $\mathrm{F}$ para peso do bacon (PB), peso da papada (PAPADA) e peso da banha rama (PBR). As linhas horizontais indicam os níveis de significância ao longo do cromossomo para QTL significativo (5\% $=$ linha fina $)$ e QTL sugestivo $(10 \%=$ linha espessa $)$.

\section{CONCLUSÕES}

Indicativos de QTL foram encontrados para peso do pernil sem pele e sem capa de gordura, peso da paleta, peso do lombo e peso do filezinho. Estes QTL são de grande interesse para os frigoríficos que visam à obtenção de melhores rendimentos dos cortes com maior valor comercial. No entanto, as regiões genômicas onde foram encontrados os indicativos de QTL devem ser mais bem investigadas para a confirmação de sua existência. 


\section{AGRADECIMENTOS}

Os autores agradecem ao CNPq (Conselho Nacional de Desenvolvimento Científico e Tecnológico) pela concessão da bolsa de estudos, à FAPEMIG (Fundação de Amparo à Pesquisa do estado de Minas Gerais) pelo financiamento do projeto, à Embrapa Milho e Sorgo, Sete Lagoas, MG, pela disponibilização do seqüenciador automático e ao Dr. Max F. Rothschild, coordenador do Projeto Americano de Mapeamento Genômico de Suínos, pela doação dos primers de microssatélites.

\section{REFERÊNCIAS BIBLIOGRÁFICAS}

ANDERSSON, L.; ANDERSSON, K.; ANDERSSONEKLUND, L. et al. Case history in animal improvement: genetic mapping of QTLs for growth and fatness in the pig. In: PATERSON, A.H. Molecular dissection of complex traits. New York: CRC, 1998. p.241-254.

ANDERSSON, L.; HALEY, C.S.; ELLEGREN, H. et al. Genetic mapping of quantitative trait loci for growth and fatness in pigs. Science, v.263, p.1771-1774, 1994.

APPLIED BIOSYSTEMS - AmpFlSTR Identifiler PCR Amplification Kit User's Manual, Foster City, CA, 2001 (P/N 4323291).

BIDANEL; J.P.; MILAN, D.; IANNUCCELLI, N. et al. Detection of quantitative trait loci for growth and fatness in pigs. Genet. Select. Evol., v.33, p.289-309, 2001.

CASAS-CARRILLO, E.; PRILL-ADAMS, A.; PRICE, S.G. et al. Mapping genomic regions associated with growth rate in pigs. J. Anim. Sci., v.75, p.2047-2053, 1997.

CHURCHILL, G.A.; DOERGE, R.W. Empirical threshold values for quantitative trait mapping. Genetics, v.138, p.963-971, 1994.

COUTINHO, L.L., Controle molecular da síndrome do estresse suíno - PSS. In: SIMPÓSIO NACIONAL DA SOCIEDADE BRASILEIRA DE MELHORAMENTO ANIMAL, 2., 1998, Uberaba. Anais... Uberaba, 1998. p.173-175.

FUJII, J.; OTSU, K.; ZORZATO, F. et al. Identification of a mutation in the porcine ryanodine receptor associated with malignant hyperthermia. Science, v.253, p.448-451, 1991.

HALEY, C.S.; KNOTT, S.A.; ELSEN, J.M. Mapping quantitative trait loci in crosses between outbred lines using least squares. Genetics, v.36, p.1195-1207, 1994.

KONING, D.J.; JANSS, L.L.G.; RATTINK, A.P. et al. Detection of quantitative trait loci for backfat thickness and intramuscular fat content in pigs (Sus scrofa). Genetics, v.152, p.1679-1690, 1999.
MALEK, M.; DEKKERS, C.M.J.; LEE, H.K. et al. A molecular genome scan analysis to identify chromosomal regions influencing economic traits in the pig. I-Growth and body composition. Mamm.Genom., v.12, p.630-636, 2001.

ÓVILO, C.; FERNANDEZ, A.; NOGUERA, J.L. et al. Fine mapping of porcine chromosome 6 QTL and LEPR effects on body composition in multiple generations of an Iberian by Landrace intercross. Genet. Res., v.85, p.5767, 2005.

PIG genome mapping. Edinburg: Roslin Institute, 1996. Disponível em: <http://www.projects.roslin.ac.uk>. Acessado em: 15 jan. 2003.

PIRES, A.V.; LOPES, P.S.; GUIMARÃES, S.E.F. et al. Quantitative trait loci mapping for meat quality traits in swine chromosome 6. Arq. Bras. Med. Vet. Zootec., v.57, p.608-615, 2005.

PIRES, A. V.; LOPES, P.S; GUIMARÃES, S.E.F. Mapeamento de locos de características quantitativas (QTL) no cromosomo 6 de suínos, associados às características de carcaça e de órgão internos. Rev. Bras. Zootec., v.35, supl., p.1660-1668, 2006

PIRES, A. V.; LOPES, P.S.; GUIMARÃES, S.E.F. et al. Mapping quantitative trait loci for performance traits on pig chromosome 6 (SSC6). Arch. Latinoam. Prod. Anim., v. 15, p. 25-31, 2007.

ROHRER, G.A.; KEELE, J.W. Identification of quantitative trait loci affecting carcass composition in swine: II - Muscling and wholesale product yield traits. $J$. Anim. Sci., v.76, p.2255-2262, 1998.

ROTHSCHILD, M.F. U.S. Pig gene mapping coordination program. 1994. Disponível em: $<\mathrm{http}: / /$ www.genome.iastate.edu/pig $>$. Acessado em: 20 jan. 2003.

ROTHSCHILD, M.F.; PLASTOW, G.S. Advances in pig genomics and industry applications. AgBiotechNet, v.1, p.1-7, 1999.

SAMBROOK, J.; FRITSCH, E.F.; MANIATIS, T. et al. Molecular Cloning - A Laboratory Manual. 2.ed. New York: Cold Spring Habour Laboratory, 1989

SEATON, G.; HALEY, C.S.; KNOTT, S.A. et al. QTL express: mapping quantitative trait loci in simple and complex pedigrees. Bioinformatics, v.18, p.339-340, 2002.

USER'S guide: statistics. Version 6. 4.ed. Cary, NC: SAS Institute, 1990

WALLING, G.A.; VISSCHER, P.M.; ANDERSSON, L. et al. Combined analyses of data from quantitative trait loci mapping studies: chromosome 4 effects on porcine growth and fatness. Genetics, v.155, p.1369-1378, 2000.

YUE, G.; STRATIL, A.; KOPECNY, M. et al. Linkage and QTL mapping for Sus scrofa chromosome 6. J. Anim. Breed. Genet., v.120, Suppl.1, p.45-55, 2003. 